Success

\section{Success causes growing pains}

\section{B A van de Putte (editor) on behalf of the editorial team}

\section{Speeding up submission to publication}

S ince the Annals of the Rheumatic Diseases became the official journal of the European League against Rheumatism (EULAR) in 1999, the journal has undergone a time of immense growth-for example:

- Submissions have increased from about 450 in 1999 to an expected 1300 in 2005
- The impact factor has doubled (at 3.827 it is now the highest of the European rheumatology journals)

- Print circulation has more than tripled.

As might be expected, this overwhelming expansion has not been without consequence: the major negative one being an increase in the acceptance to publication time. Measures such as a strictly enforced word count, effective web usage, and an acceptance rate of only $25 \%$ have yet to have the desired impact

At the request of the editorial team, the journal's owners (BMJ Publishing Group and EULAR) have agreed to increase the size of the next six issues of ARD significantly to reduce the publication lead time; in addition, the average page budget for the journal will be increased to sustain a reduced time to publication.

We hope that you will continue to enjoy the journal and its greatly enlarged size.

PS. Readers should also note that selected articles are published Online First-within days of acceptance-on $A R D^{\prime}$ s website (http://ard.bmjjournals. com/onlinefirst.shtml). See p 1034.

Ann Rheum Dis 2004;63:1007 example, one study found that only $29 \%$ of attempted subacromial injec-

\title{
Do imaging methods that guide needle placement improve outcome?
}

\section{S Hall, R Buchbinder}

\section{For most joints injections following an anatomical landmark are sufficient}

$\mathrm{T}$ he year 1949 was a watershed for rheumatology. In that year Hench and his colleagues first described the use of corticosteroids for therapy in rheumatoid arthritis. Within a year Hollander and his colleagues, having seen the striking topical anti-inflammatory effects of cortisone, injected cortisone suspension into 25 knee joints inflamed by rheumatoid arthritis, but found only a minimal and transitory benefit. ${ }^{1}$ However, by 1954, depot steroid preparations for intra-articular injection were part of the standard therapeutic armamentarium. ${ }^{1}$

\section{ACCURACY OF NEEDLE PLACEMENT}

Despite the enthusiasm with which injected corticosteroids have been greeted and their widespread continued use, until recently, there has been limited evidence from controlled trials of their effectiveness in conditions such as shoulder disorders. ${ }^{2}$ Furthermore, for the first 40 years of their use, the accuracy of needle placement was not methodically studied. In 1993, Jones et al studied the accuracy of 109 injections into various joints, by mixing the depot steroid with a radiographic contrast medium. ${ }^{3}$ They found that approximately one third of knee and ankle injections were extra-articular, only half of the wrist injections were definitely intra-articular, with even less accuracy reported for shoulder injections. Remarkably, even the ability to aspirate synovial fluid was not a perfect predictor of intra-articular placement of steroid injections with almost half of extra-articular injections having been associated with successful aspiration of synovial fluid. Experience beyond advanced trainee/registrar level did not appear to influence the accuracy of injection placement. Despite these findings, almost half of those with extraarticular placement experienced good therapeutic response, suggesting that total accuracy of needle placement may not be essential to a satisfactory outcome.

\section{"Total accuracy of needle placement may not be essential"}

Subsequent studies have reported variable rates of accuracy of corticosteroid tions and $42 \%$ of attempted glenohumeral injections were accurately placed, ${ }^{4}$ while another study found that subacromial injection was accurate in $87 \%$ of cases. ${ }^{5}$ Based upon these studies, it is reasonable to estimate that successful subacromial placement occurs in around $70 \%$ of cases. ${ }^{4-7}$ A similar figure of around $70 \%$ has been reported for anterolateral and anteromedial intraarticular injection of the knee in patients without a clinical knee effusion, ${ }^{8}$ and the accuracy of "blind" injection into the basal joint of the thumb was recently estimated to be more than $80 \% .{ }^{9}$

\section{IMAGING METHODS TO ASSIST NEEDLE PLACEMENT}

A variety of imaging methods, including $x$ ray screening, computed tomography (CT) scanning and, more recently, ultrasound and magnetic resonance imaging (MRI), have been used to better localise needle placement. For example, Balint et al found that ultrasound improved the overall success of joint fluid aspiration from $32 \%$ to $97 \% .^{10}$ Similarly, another study found that ultrasound guided needle placement resulted in significantly greater accuracy than a palpation guided approach for injection of the small joints of the hand (proximal interphalangeal and metacarpophalangeal) in early rheumatoid arthritis. ${ }^{11}$ Ultrasound has also been found to be clinically better than clinical examination in determining the presence and localisation of knee joint effusions in rheumatoid arthritis. ${ }^{12}$ With the advent of vertically open MRI, there has also been an increase in MR guided interventional musculoskeletal 
procedures involving bone, joints, soft tissue, and intervertebral discs. ${ }^{13}$

\section{OUTCOME WITH GUIDED INJECTIONS}

Having established that imaging allows greater accuracy of injection, the question arises as to whether guided injection produces a significantly different result from injections administered using anatomical landmarks. Two shoulder studies have suggested an association between accuracy of steroid placement and better clinical outcome of shoulder symptoms. ${ }^{4}{ }^{14}$ In an open study involving 37 patients, Eustace et al reported that patients whose injections had been accurately placed improved to a greater degree in the short term than those whose injections had been less accurately placed. ${ }^{4}$ Recently, Naredo and colleagues studied 41 patients who were randomised to receive either a blind or sonographic guided subacromial injection of depot steroid. ${ }^{14}$ The outcome assessor, but not the patients, was blinded to the injection technique and sonographic findings. Significantly greater improvements in both shoulder function and pain were observed in patients who had received sonographic guided corticosteroid injection and this was accompanied by greater accuracy of needle placement.

Successful injection of de Quervain's tendinitis may also be predicted on the basis of the accuracy of placement of depot steroid. ${ }^{15}$ Zingas et al reported that 15/24 patients who had demonstrated intra-sheath injection of depot steroid improved, compared with $0 / 3$ patients with extra-tendon sheath injection. ${ }^{15}$ In contrast, injection into the tendon sheath for trigger finger does not seem to be required for effective pain relief and peritendinous injection appears as effective. ${ }^{16}$ Similarly, ultrasound guided steroid injection for recalcitrant plantar fasciitis has been demonstrated to be as effective as palpation guided injection in a randomised trial involving 24 patients. ${ }^{17}$

In this issue of the Annals, Shanahan et al report the results of a randomised single blind trial comparing suprascapular nerve block given by an anatomical landmark approach with a CT guided approach for chronic shoulder pain in 67 patients with 77 affected shoulders. ${ }^{18}$ Both patient groups improved substantially after injection, and CT guidance did not confer any added benefit over the anatomical landmark approach.

These findings suggest we cannot automatically assume that guided injections result in greater clinical benefits. The majority of early studies retrospectively correlated clinical outcomes with steroid placement. Although these studies suggest an association between accuracy and outcome, they do not provide definitive proof of a causal relationship, as other factors that may have influenced outcome may not have been equally distributed between the groups being compared. The majority of prospective studies published to date, while incorporating a blinded outcome assessor, have not always blinded the participants, which may also have biased their results. On the one hand, patients may expect that their rheumatologist will correctly position the injection, whereas other patients may assume that imaging will increase its accuracy.

\section{QUESTIONS REMAIN}

The fundamental issues relating to steroid injections still remain. Do corticosteroid injections provide long term benefit or are the benefits purely short term? Do radiologically guided corticosteroid injections confer any added clinical benefit over blinded injections in the short and long term? If there are added benefits, is the routine use of imaging to improve the accuracy of steroid placement, cost effective?

Any added benefit in patient outcome achieved by a radiologically guided approach will need to be considered in light of the added expense of the imaging modality used. Although some rheumatologists may use office ultrasound, it is likely that in community practice it will be radiologists who employ ultrasound and other imaging techniques to administer injections, and this may be associated with significant increase in overall health costs. Any decision as to the cost effectiveness of such injections relies on data provided by good randomised, controlled trials with long term follow up, such as that reported by Shanahan et al. ${ }^{18}$

It remains for proponents of imaging guided injections to demonstrate that employing this approach does more than improve short term outcomes, but makes a real difference over the longer term sufficient to justify the extra cost. Until such data are available, it seems reasonable to conclude that while some joints such as the hip and midtarsal joints demand imaging for any accuracy of steroid placement, for most joints which have conventionally been injected by rheumatologists following an anatomical landmark approach, imaging guided injection should be reserved for those cases who have not responded to injection following anatomical landmarks.

\section{Ann Rheum Dis 2004;63:1007-1008.} doi: 10.1136/ard.2004.020685

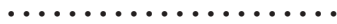

\section{Authors' affiliations}

S Hall, Department of Medicine, Monash University, Box Hill Hospital, and Cabrini Hospital, Melbourne, Australia
R Buchbinder, Monash Department of Clinical Epidemiology at Cabrini Hospital; Department of Epidemiology and Preventive Medicine, Monash University, Melbourne, Australia

Correspondence to: Associate Professor R Buchbinder, Monash Department of Clinical Epidemiology, Suite 41 Cabrini Medical Centre, 183 Wattletree Rd, Malvern, Victoria, Australia 3144; rachelle.buchbinder@med.monash.edu.au

\section{REFERENCES}

1 Hollander JL. In: McCarty DJ, ed. Arthritis and allied conditions. Philadelphia: Lea \& Febiger, 1979 2 Buchbinder R, Green S, Youd JM. Corticosteroid injections for shoulder pain [Cochrane review]. In: The Cochrane Library, Issue 2. Chichester, UK: John Wiley \& Sons, 2004

3 Jones A, Regan M, Ledingham J, Patrick M, Manhire A, Doherty M. Importance of placement of intra-articular steroid injections. BMJ 1993:307:1329-30.

4 Eustace JA, Brophy DP, Gibney RP, Bresnihan B FitzGerald $O$. Comparison of the accuracy of steroid placement with clinical outcome in patients with shoulder symptoms. Ann Rheum Dis 1997;56:59-63.

5 Esenyel CZ, Esenyel M, Yesiltepe R, Ayanoglu S, Bulbul MM, Kara AN. Acta Orthop Traumatol Turc 2003;37:41-5.

6 Partington PF, Broome GH. Diagnostic injection around the shoulder: hit and miss? A cadaveric study of injection accuracy. J Shoulder Elbow Surg 1998;7:147-50

7 Yamakado K. The targeting accuracy of subacromial injection to the shoulder: an arthrographic evaluation. J Arthroscop Rel Surg 2002; 18:887-91.

8 Jackson DW, Evans NA, Thomas BM. Accuracy of needle placement in the intra-articular space of the knee. J Bone Joint Surg Am 2002:84:1522-7.

9 Pollard MA, Cermak MB, Williams DP, Buck WR. Accuracy of injection into the basal joint of the thumb. Orthopedics 2003;(suppl):4.

10 Balint PV, Kane D, Hunter J, Mclnnes IB, Field M, Sturrock RD. Ultrasound guided versus conventional joint and soft tissue fluid aspiration in rheumatology practice: a pilot study. J Rheumatol 2002;29:2209-13.

11 Raza K, Lee CY, Pilling D, Heaton S, Situnayake RD, Carruthers DM, et al. Ultrasound guidance allows accurate needle placement and aspiration from small joints in patients with early inflammatory arthritis. Rheumatology (Oxford) 2003:42:976-9

12 Kane D, Balint PV, Sturrock RD. Ultrasonography is superior to clinical examination in the detection and localization of knee joint effusion in rheumatoid arthritis. J Rheumatol 2003;30:966-71.

13 Genant JW, Vandavenne JE, Bergman G, Beaulieu CF, Kee ST, Norbash AM, et al. Interventional musculoskeletal procedures performed by using MR imaging guidance with a vertically open MR unit: assessment of techniques and applicability. Radiology 2002;223:127-36.

14 Naredo E, Cabero F, Beneyto P, Cruz A Mondéjar B, Uson J, et al. A randomized comparative study of short term response to injection versus sonographic-guided injection of local corticosteroids in patients with painful shoulder. J Rheumatol 2004;31:308-14.

15 Zingas C, Failla JM, Van Holsbeeck M. Injection accuracy and clinical relief of de Quervain's tendinitis. J Hand Surg [Am] 1998;23:89-96.

16 Taras JS, Raphael JS, Pan WT, Movagharnia F Sotereanos DG. Corticosteroid injections for trigger digits: is intrasheath injection necessary? J Hand Surg [Am] 1998;23;717-22.

17 Kane D, Greaney T, Shanahan M, Duffy G, Bresnihan B, Gibney R, et al. The role of ultrasonography in the diagnosis and management of idiopathic plantar fasciitis. Rheumatology (Oxford) 2001;9:1002-8.

18 Shanahan EM, Smith MD, Wetherall M, Lott CW, Slavotinek J, FitzGerald O, et al. Suprascapular nerve block in chronic shoulder pain: are the radiologists better? Ann Rheum Dis 2004;63:1035-40. 